\title{
Honey, trehalose and erythritol as sucrose-alternative sweeteners for artisanal ice cream. A pilot study
}

\author{
Maria Eletta Moriano, Cristina Alamprese* \\ Department of Food, Environmental and Nutritional Sciences (DeFENS), Università degli Studi di Milano, via G. Celoria 2, 20133, Milan, Italy
}

\section{A R T I C L E I N F O}

\section{Article history}

Received 5 May 2016

Received in revised form 22 July 2016

Accepted 29 August 2016

Available online $\mathrm{xxx}$

\section{Keywords:}

Artisanal ice cream

Sweetener

Honey

Trehalose

Erythritol

\begin{abstract}
A B S T R A C T
The use of sucrose-alternative sweeteners in ice cream production could satisfy requirements of modern consumers focused on natural and nutritionally balanced foods. The aim of this work was to fill the gap in basic knowledge about the effects of honey, trehalose, and erythritol on the properties of artisanal ice cream. A milk-based sucrose-sweetened ice cream was produced as reference sample (REF), using then the alternative sweeteners to partially $(50 \%)$ or totally $(100 \%)$ substitute sucrose. With respect to REF, honey-containing ice cream mix revealed a significantly lower value of soluble solids ( $\left.30.4^{\circ} \mathrm{Bx} v s .34 .5^{\circ} \mathrm{Bx}\right)$ and apparent viscosity $(36.5 \mathrm{mPa}$ s $v s .47 .6 \mathrm{mPa} \mathrm{s})$ and a significantly higher extrusion time $(8.18 \mathrm{~min} v s .7 .04 \mathrm{~min})$. The total substitution of sucrose with trehalose and erythritol led to a melting rate (2.07 and $1.56 \mathrm{~g} / \mathrm{min}$, respectively) significantly lower than REF $(2.75 \mathrm{~g} / \mathrm{min})$, a very high firmness $(508$ and $725 \mathrm{~N} v s$. $4 \mathrm{~N}$ ), and a higher extrusion temperature $\left(-7.1\right.$ and $\left.-5.3{ }^{\circ} \mathrm{C} v s .-9.3{ }^{\circ} \mathrm{C}\right)$. The results of this study represent a guideline for the successfully utilization of honey, trehalose, and erythritol in peculiar ice cream formulations (e.g. non-sweet or low-calorie products).
\end{abstract}

(C) 2016 Published by Elsevier Ltd.

\section{Introduction}

In recent years, the market for foods claiming nutritionally balanced profile and healthy characteristics has steadily grown, as well as demand for natural products. Health and fitness, together with cultural and ethical concerns, have designed new behaviors towards food selection (Falguera, Aliguer, \& Falguera, 2012). Thus, researchers continuously focus on reformulating products traditionally rich in saturated fat and sugar using healthier ingredients with positive physiological effects. In this context, efforts have been made to transform ice cream from indulgent snack and dessert into a nutritionally and physiologically beneficial product, without renouncing to the pleasure of consumption (Akalin \& Erisir, 2008; Akalin, Karagözlü, \& Ünal, 2008; Rossa, Burin, \& Bordignon-Luiz, 2012; Sun-Waterhouse, Edmonds, Wadhwa, \& Wibisono, 2013).

Substituting the traditional sweeteners, i.e. sucrose and glucose syrup, with other bulk sweeteners affects, beyond sensory properties, the freezing behavior and the stability of the ice cream (Cadena, Cruz, Faria, \& Bolini, 2012; Hagiwara \& Hartel, 1996; Muse \& Hartel, 2004; Ozdemir, Dagdemir, Ozdemir, \& Sagdic, 2008). Thus, the substitution strategy may give uncertain results in terms of physico-chemical and sensory properties of the final product and experimental trials are needed to clarify the effects of the different sucrose alternatives present on the market.

Among sucrose alternatives, honey is one of the oldest natural sweeteners; its use in artisanal production may add a unique value to ice cream, due to the characteristic aromatic profile and the positive

\footnotetext{
* Corresponding author.

Email address: cristina.alamprese@unimi.it (C. Alamprese)
}

effects on consumers' health. Honey has a medium glycemic index (GI) of 55 (Foster-Powell, Holt, \& Brand-Miller, 2002) in comparison to sucrose $(\mathrm{GI}=100)$. It has been claimed to promote the reduction of blood glucose levels in diabetics (Busserolles, Gueux, Rock, Mazur, \& Rayssiguier, 2002), as well as a marked reduction of plasmatic triglycerides (Al-Waili, 2004).

Other new alternative-sweeteners have recently gained the attention of ice cream producers due to their unique properties. For instance, trehalose, naturally occurring in some foods (i.e. honey, mushrooms, yeasts, shellfish), is interesting for its stabilizing effect on systems subjected to freezing and thawing processes (Richards et al., 2002). It is a disaccharide made up of two D-glucose molecules linked by an $\alpha, \alpha-1,1$ bond, showing a relative sweetness of 0.45 (Portmann $\&$ Birch, 1996). Another recent alternative to sucrose is represented by erythritol (1,2,3,4-butanetetrol), a natural polyalcohol found in small quantities in fruits, vegetables, mushrooms and fermented foods. It has a sweetening power of approximately 0.7 in comparison to sucrose, with a mild cooling effect and no after taste (Mitchell, 2006). The interest in erythritol is due to its high stability towards temperature and extreme $\mathrm{pH}$ conditions (Boesten et al., 2015), zero-calorie value, zero GI, and non-cariogenic properties (Mitchell, 2006; Whelan, Vega, Kerry, \& Goff, 2008b). Moreover, unlike other polyols, erythritol shows a high intestinal tolerance (Arrigoni, Brouns, \& Amadò, 2007).

Very few studies deal with the effects of using honey, threalose, and erythritol as sucrose alternatives in ice cream production (Fuangpaiboon \& Kijroongrojana, 2013, 2015; Ozdemir et al., 2008; Whelan et al., 2008b; Whelan, Regand, Vega, Kerry, \& Goff, 2008a). In addition, these alternative sweeteners have been mainly considered in complex systems, with the aim to develop a complete ice cream formulation, with optimal quality characteristics. Sucrose substitution 
was mainly carried out with the new sweeteners in combination with other ingredients (e.g. polidextrose), thus hindering the real effect of the single ingredient. Thus, the aim of this study was to systematically evaluate the effects of honey, trehalose, or erythritol on the quality characteristics of artisanal ice cream. A partial or complete substitution of sucrose in basic formulations with a high added sugar content $(20 \mathrm{~g} / 100 \mathrm{~g})$ has been studied, in order to enhance the role of the single sweetener used and draw basic information useful for an easier application.

\section{Materials and methods}

\subsection{Ice cream formulations}

Reference ice cream (REF) was formulated as reported in Table 1, with fresh pasteurized whole milk (Centrale del Latte di Milano, Milan, Italy), pasteurized cream (Centrale del Latte di Milano, Milan, Italy), skim milk powder (Comprital S.p.A., Settala, Milan, Italy), stabilizers and emulsifiers (Neumilk 5C, Comprital S.p.A.) and sucrose (Comprital S.p.A). In experimental samples sucrose was partially $(50 \%)$ or completed $(100 \%)$ substituted on a weight basis with multifloral honey, crystalline trehalose dihydrate, or erythritol. All the formulations had the same total solid content $(36.5 \mathrm{~g} / 100 \mathrm{~g})$, with the exception of samples produced with $50 \%$ or $100 \%$ sucrose substitution with honey (H50 and H100, respectively). Due to the water contained in honey (about $18 \mathrm{~g} / 100 \mathrm{~g}$, according to Ozdemir et al., 2008), H50 and $\mathrm{H} 100$ had a total solid content of about $34.7 \mathrm{~g} / 100 \mathrm{~g}$ and $32.9 \mathrm{~g} /$ $100 \mathrm{~g}$, respectively. A basic ice cream formulation with a high content of added sugars $(20 \mathrm{~g} / 100 \mathrm{~g})$ was used, in order to enhance the real effect of the different sweeteners.

Honey and all powder ingredients were kindly supplied by Comprital S.p.A., with the exception of trehalose (Hayashibara, Okayama, Japan) and erythritol (Giusto Faravelli S.p.A., Milan, Italy). Experimental samples were identified by a code consisting of a letter and a number: the letter refers to the type of sweetener used $(\mathrm{H}$, honey; $\mathrm{T}$, trehalose; E, erythritol) and the number to the percentage of sucrose substitution $(100 \%$ or $50 \%)$.

\subsection{Ice cream production}

Ice cream mixes were prepared as reported in Rossi, Casiraghi, Alamprese, and Pompei (1999), by using a Pastomaster 60 Tronic and a Labotronic 20-30 batch freezer (Carpigiani S.r.1, Anzola Emilia, Italy). Briefly, pasteurization was carried out up to $85^{\circ} \mathrm{C}$ for $30 \mathrm{~s}$ on a $15 \mathrm{~kg}$ batch, with continuous mix circulation. After $24 \mathrm{~h}$ ageing at $4{ }^{\circ} \mathrm{C}$, the mix was frozen in four aliquots ( $3 \mathrm{~L}$ each) and packed either in $230 \mathrm{~mL}$ HDPE lid containers or in smaller $50 \mathrm{~mL}$ polythene hinged-lid containers. Ice cream samples were stored for $24 \mathrm{~h}$ at $-30{ }^{\circ} \mathrm{C}$ and then conditioned for $24 \mathrm{~h}$ at $-16^{\circ} \mathrm{C}$ before

Table 1

Formulation and composition of the reference ice cream (REF).

\begin{tabular}{lllll}
\hline Ingredient & $\begin{array}{l}\text { Amount } \\
(\%)\end{array}$ & $\begin{array}{l}\text { Fat }(\mathrm{g} / \\
100 \mathrm{~g})\end{array}$ & $\begin{array}{l}\text { MSNF }(\mathrm{g} / \\
100 \mathrm{~g})\end{array}$ & $\begin{array}{l}\text { Total solids }(\mathrm{g} / \\
100 \mathrm{~g})\end{array}$ \\
\hline Whole milk & 64.5 & 2.42 & 5.39 & 7.8 \\
Milk cream & 10.5 & 3.68 & 0.57 & 4.2 \\
Skim milk powder & 4.5 & 0.03 & 3.96 & 4.0 \\
Sucrose & 20.0 & & & 20.0 \\
Emulsifier and & 0.5 & & & 0.5 \\
$\quad$ stabilizers & & & & 36.5 \\
Total & 100.0 & 6.13 & 9.91 & \\
\hline
\end{tabular}

MSNF, milk solids not fat. analyses. Two technological replicates were carried out for each formulation. During production the time lasting from the beginning of mix freezing until the extrusion of ice cream was measured by a timer (extrusion time). The ice cream extrusion automatically occurs at a given level of stress (pre-determined by the equipment constructor) registered by the freezer dasher. Immediately after extrusion, the ice cream temperature was determined inserting a thermometer in the center of the product, just before packaging.

\subsection{Relative freezing point depression of sweeteners}

In order to calculate the relative freezing point depression (FPD) of sweeteners, osmolality (mOsmol/ $\mathrm{kg}$ ) of $20 \mathrm{~g} / 100 \mathrm{~mL}$ aqueous solutions of sucrose, trehalose and erythritol was measured by a Semi-Micro Osmometer K-7400 (Knauer, Berlin, Germany). Results were converted in freezing points (FP) by means of the following equation:

FP $\left({ }^{\circ} \mathrm{C}\right)=-0.0019 \cdot$ osmolality $(\mathrm{mOsmol} / \mathrm{kg})+0.0009$

Relative FPD was then calculated as the ratio between the freezing point of the solution containing sucrose and the freezing point of the solution containing the considered sweetener.

\subsection{Ice cream mix analyses}

Analyses of ice cream mixes were carried out after $24 \mathrm{~h}$ ageing at $4{ }^{\circ} \mathrm{C}$. Mix density was determined at $4{ }^{\circ} \mathrm{C}$ measuring the weight of a fixed volume $(50 \mathrm{~mL})$ of mix. Results are expressed as the average of three replicates $(\mathrm{g} / \mathrm{mL})$. The quantity of soluble solids was determined at $4{ }^{\circ} \mathrm{C}$ by a digital refractometer DBX-55 (Atago, Tokyo, Japan) and expressed as the average of at least five measurements $\left({ }^{\circ} \mathrm{Bx}\right)$. Flow curves were measured at $4{ }^{\circ} \mathrm{C}$ using a Physica MCR 300 rheometer (Anton Paar, Graz, Austria) equipped with coaxial cylinders (CC27), in a $20-500 \mathrm{~s}^{-1}$ range of shear rate. Results are expressed as the average of two replicates in terms of apparent viscosity (mPa s) at $290 \mathrm{~s}^{-1}$. This shear rate value has been chosen in a portion of the flow curve where the viscosity is not greatly influenced by the shear rate itself. Flow curves were also fitted by the power law equation (Eq. (2)), in order to calculate the consistency coefficient $(\mathrm{K})$ and the flow behavior index(n):

$$
\tau=K \cdot \dot{\gamma}^{n}
$$

where $\tau$ is the shear stress $(\mathrm{mPa})$ and $\dot{\gamma}$ is the shear rate $\left(\mathrm{s}^{-1}\right)$ (Steffe, 1996).

\subsection{Ice cream analyses}

Overrun, firmness and melting behavior of ice cream samples were determined as reported in Rossi et al. (1999) and Alamprese, Foschino, Rossi, Pompei, and Savani (2002).

Ice cream ability to retain its shape during melting was evaluated through an image analysis method. Pictures of the samples during melting test were taken with a DSC-S650 (Sony Corp, Tokyo, Japan) camera in standard conditions at fixed time intervals of $15 \mathrm{~min}$, for a total time of $90 \mathrm{~min}$. Image Pro Plus 7.0 software (Media Cybernetics Inc., Rockville, MD, USA) was used to analyze the images and determine ice cream sample height (h), width (w), and area (A). The dimensional parameters were used to determine the following shape retention indexes: $R_{t}$, ratio between $h$ and $w$, calculated at different 
times $(0,15,30,45,60,75,90 \mathrm{~min}) ; \mathrm{R}_{\mathrm{t}} / \mathrm{R}_{0}$, ratio between dimensions at different times referred to the initial ratio $\left(\mathrm{R}_{0}\right) ; \mathrm{A}_{\mathrm{t}}$, ice cream area measured at different times $(0,15,30,45,60,75,90 \mathrm{~min}) ; \mathrm{A}_{\mathrm{t}} / \mathrm{A}_{0}$, ratio between the area at each time referred to the initial time $(0 \mathrm{~min})$.

\subsection{Statistical analysis}

One-way analysis of variance (ANOVA) was applied to the analytical data in order to compare each experimental ice cream formulation to the reference sample (REF). The Least Significant Difference (LSD) test at $\mathrm{p}<0.05$ was used to evaluate significant differences among the averages (Statgraphics Plus 5.1, Statistical Graphics Corp., Herndon, VA, USA).

\section{Results and discussion}

\subsection{Ice cream mix properties}

Mix density, soluble solids and viscosity results are reported in Table 2. The total substitution of sucrose with honey and trehalose (H100 and T100) caused a significant $(\mathrm{p}<0.05)$ but very slight decrease in ice cream mix density. As expected, honey-containing samples (H100 and H50) revealed an amount of total soluble solids lower than REF, due to the water contribution of honey. This effect most likely caused also the significant $(\mathrm{p}<0.05)$ decrease of the apparent viscosity. On the contrary, Ozdemir et al. (2008) reported a significantly increased apparent viscosity in mixes produced with total $(100 \%)$ and partial $(50 \%)$ substitution of sucrose with honey and attributed the results to the viscosity of this ingredient. The apparent

Table 2

Properties of ice cream mixes (mean \pm s.d. values of two technological replicates).

\begin{tabular}{llllll}
\hline & $\begin{array}{l}\text { Density }(\mathrm{g} / \\
\mathrm{mL})\end{array}$ & $\begin{array}{l}\text { Soluble } \\
\text { solids } \\
\left({ }^{\circ} \mathrm{Bx}\right)\end{array}$ & $\begin{array}{l}\text { Apparent } \\
\text { viscosity } \\
(\mathrm{mPa})\end{array}$ & $\mathrm{K}(\mathrm{mPa} \mathrm{s})$ & $\mathrm{n}(-)$ \\
\hline REF & $1.12 \pm 0.01^{\mathrm{a}}$ & $34.5 \pm 0.9^{\mathrm{a}}$ & $47.60 \pm 1.56^{\mathrm{a}}$ & $118.64 \pm 8.30^{\mathrm{a}}$ & $0.842 \pm 0$. \\
H100 & $1.09 \pm 0.01^{\mathrm{b}}$ & $30.4 \pm 0.1^{\mathrm{b}}$ & $36.50 \pm 0.11^{\mathrm{b}}$ & $85.75 \pm 1.84^{\mathrm{b}}$ & $0.852 \pm 0$. \\
H50 & $1.10 \pm 0.01^{\mathrm{a}}$ & $32.6 \pm 0.4^{\mathrm{a}}$ & $40.27 \pm 1.68^{\mathrm{b}}$ & $89.29 \pm 6.61^{\mathrm{a}}$ & $0.860 \pm 0$. \\
T100 & $1.02 \pm 0.02^{\mathrm{b}}$ & $35.9 \pm 0.3^{\mathrm{a}}$ & $46.08 \pm 0.91^{\mathrm{a}}$ & $112.47 \pm 5.26^{\mathrm{a}}$ & $0.842 \pm 0$. \\
T50 & $1.11 \pm 0.01^{\mathrm{a}}$ & $34.3 \pm 0.1^{\mathrm{a}}$ & $44.45 \pm 1.29^{\mathrm{a}}$ & $105.33 \pm 5.75^{\mathrm{a}}$ & $0.848 \pm 0$. \\
E100 & $1.09 \pm 0.01^{\mathrm{a}}$ & $34.3 \pm 0.7^{\mathrm{a}}$ & $48.93 \pm 1.24^{\mathrm{a}}$ & $145.28 \pm 10.89^{\mathrm{a}}$ & $0.808 \pm 0$. \\
E50 & $1.10 \pm 0.01^{\mathrm{a}}$ & $34.2 \pm 0.4^{\mathrm{a}}$ & $53.05 \pm 1.06^{\mathrm{a}}$ & $178.60 \pm 19.27^{\mathrm{a}}$ & $0.786 \pm 0$.
\end{tabular}

$\overline{\mathrm{a}, \mathrm{b}}$ Results with different superscript letters in the same column are significantly different $(\mathrm{p}<0.05)$ from the reference $(\mathrm{REF})$.

$\mathrm{K}$, consistency coefficient; $\mathrm{n}$, flow behavior index. viscosity of the other mixes was similar to REF, ranging from 44.45 to $53.05 \mathrm{mPa}$.

All the ice cream mixes showed a non-Newtonian shear thinning (pseudoplastic) behavior (Fig. 1). In fact, fitting shear stress and shear rate data with the power law equation [Eq. (2)] a flow behavior index (n) lower than 1 was calculated (Table 2), with correlation coefficients (r) higher than 0.999 . Similar values of $\mathrm{n}$ were calculated for all the mixes, ranging from 0.786 to 0.860 . As regards the consistency coefficient $(\mathrm{K})$, only the sample H100 showed a significantly $(\mathrm{p}<0.05)$ lower value in comparison to REF, in agreement with the significantly lower value of the apparent viscosity.

\subsection{Ice cream properties}

Table 3 reports the results related to the ice cream extrusion process. Samples E50 and H100 showed a significant $(\mathrm{p}<0.05)$ increase in extrusion time, although the temperature values did not significantly differ from REF. Trehalose-containing samples showed a significantly $(p<0.05)$ lower extrusion temperature than the reference, suggesting a lower ability of this sweetener to decrease the freezing point in comparison with sucrose. Actually, trehalose showed a relative FPD of $0.90 \pm 0.01$, significantly $(p<0.05)$ lower than those of sucrose, as already reported by Whelan et al. (2008a). A particular and unexpected behavior was observed for the ice cream containing erythritol (E100) that reached the consistency required for the extrusion at a higher temperature and with a longer freezing process (higher extrusion time) than sucrose. One may argue that erythritol did not cause a freezing point depression comparable to that of the other sugars. However, this hypothesis is apparently in contrast with the very low molecular weight $(122.2 \mathrm{~g} / \mathrm{mol})$ of erythritol (Moon, Jeya, Kim, \& Lee, 2010), supposed to strongly affect the solution freezing dynamic (Goff \& Hartel, 2013). Osmolality measurements carried out on erythritol solutions $(20 \mathrm{~g} / 100 \mathrm{~mL})$ apparently confirm the ability of this sugar to lower the freezing point of the system more than sucrose (relative FPD $=2.41 \pm 0.01$ ). Theoretically, as calculated through the equation reported by Whelan et al. (2008b), the ice cream mix E100 should have shown a freezing point of $-4.40{ }^{\circ} \mathrm{C}$ compared to $-3.04{ }^{\circ} \mathrm{C}$ of the reference containing sucrose. Thus, the apparent inconsistency between the extrusion parameters and the sugar properties may be due to the low water solubility of erythritol: $36 \%$ at $25{ }^{\circ} \mathrm{C}$ compared to the $67 \%$ of sucrose (O'Brien-Nabors, 2001). In addition, the low temperatures reached during ice cream production enhance the insolubility of the sweetener, reducing the amount of solubilized sugar and, consequently, the freezing point depression effect.
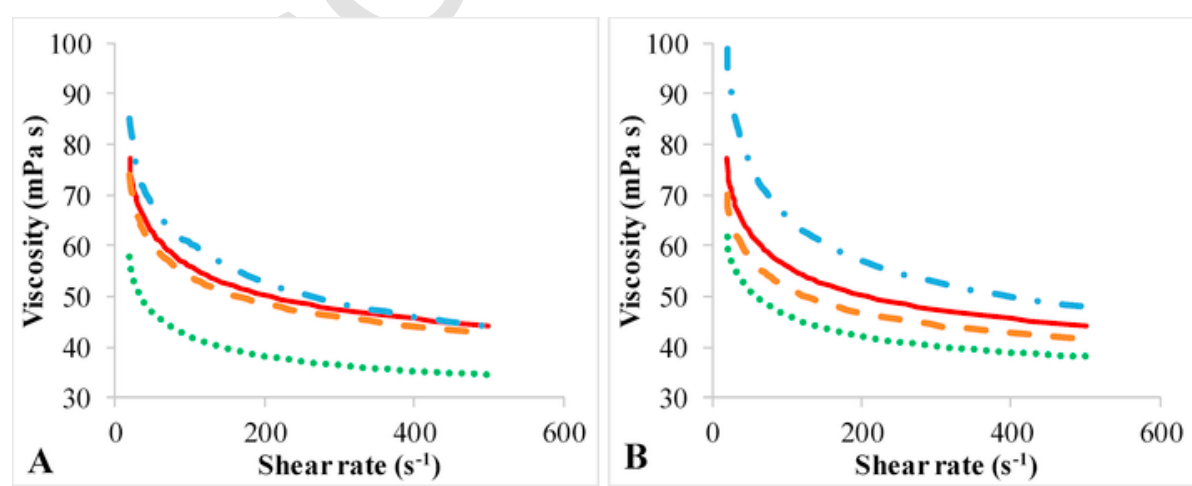

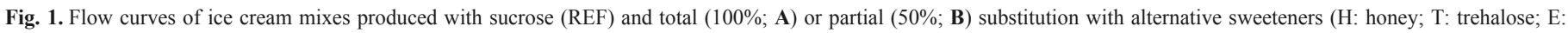

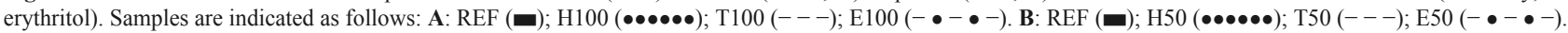


Table 3

Extrusion parameters of ice cream samples (mean \pm s.d. values of two technological replicates).

\begin{tabular}{lll}
\hline Sample & Extrusion time $(\min )$ & Extrusion temperature $\left({ }^{\circ} \mathrm{C}\right)$ \\
\hline REF & $7.04 \pm 0.13^{\mathrm{a}}$ & $-9.3 \pm 0.2^{\mathrm{a}}$ \\
H100 & $8.18 \pm 0.18^{\mathrm{b}}$ & $-10.5 \pm 0.7^{\mathrm{a}}$ \\
H50 & $7.31 \pm 0.71^{\mathrm{a}}$ & $-8.3 \pm 0.1^{\mathrm{b}}$ \\
T100 & $7.42 \pm 0.29^{\mathrm{a}}$ & $-7.1 \pm 0.3^{\mathrm{b}}$ \\
T50 & $6.50 \pm 0.21^{\mathrm{a}}$ & $-8.1 \pm 0.1^{\mathrm{b}}$ \\
E100 & $11.20 \pm 0.01^{\mathrm{b}}$ & $-5.3 \pm 0.2^{\mathrm{b}}$ \\
E50 & $9.53 \pm 0.39^{\mathrm{b}}$ & $-7.6 \pm 0.6^{\mathrm{a}}$ \\
\hline
\end{tabular}

$\overline{\mathrm{a}, \mathrm{b}}$ Results with different superscript letters in the same column are significantly different $(\mathrm{p}<0.05)$ from the reference $(\mathrm{REF})$.

Table 4

Physical properties of ice cream samples (mean \pm s.d. values of two technological replicates).

\begin{tabular}{lllll}
\hline Sample & Overrun $(\%)$ & Firmness $(\mathrm{N})$ & \multicolumn{2}{l}{ Melting behavior } \\
\hline & & & $\mathrm{t}_{\mathrm{s}}(\mathrm{min})$ & Rate $(\mathrm{g} / \mathrm{min})$ \\
\hline REF & $47.6 \pm 2.3^{\mathrm{a}}$ & $4.04 \pm 0.39^{\mathrm{a}}$ & $18 \pm 1^{\mathrm{a}}$ & $2.75 \pm 0.09^{\mathrm{a}}$ \\
H100 & $35.7 \pm 1.1^{\mathrm{b}}$ & $2.94 \pm 0.02^{\mathrm{a}}$ & $20 \pm 1^{\mathrm{a}}$ & $2.60 \pm 0.03^{\mathrm{a}}$ \\
H50 & $40.5 \pm 2.8^{\mathrm{a}}$ & $3.98 \pm 0.01^{\mathrm{a}}$ & $19 \pm 1^{\mathrm{a}}$ & $2.59 \pm 0.01^{\mathrm{a}}$ \\
T100 & $39.8 \pm 0.8^{\mathrm{b}}$ & $508.50 \pm 22.21^{\mathrm{b}}$ & $20 \pm 1^{\mathrm{a}}$ & $2.07 \pm 0.16^{\mathrm{b}}$ \\
T50 & $47.2 \pm 1.3^{\mathrm{a}}$ & $3.70 \pm 0.35^{\mathrm{a}}$ & $19 \pm 1^{\mathrm{a}}$ & $2.57 \pm 0.01^{\mathrm{a}}$ \\
E100 & $50.9 \pm 1.0^{\mathrm{a}}$ & $725.46 \pm 22.70^{\mathrm{b}}$ & $22 \pm 2^{\mathrm{a}}$ & $1.56 \pm 0.20^{\mathrm{b}}$ \\
E50 & $46.1 \pm 3.0^{\mathrm{a}}$ & $16.58 \pm 0.64^{\mathrm{b}}$ & $9 \pm 2^{\mathrm{b}}$ & $3.24 \pm 0.12^{\mathrm{b}}$
\end{tabular}

a,b Results with different superscript letters in the same column are significantly different $(\mathrm{p}<0.05)$ from the reference $(\mathrm{REF})$.
As reported in Table 4, all the ice cream samples had an overrun comparable to the reference, except for H100 and T100 that showed significant lower values $(\mathrm{p}<0.05)$, probably due to the lower density of the corresponding mixes (Table 2). The only use of honey as sweetener caused a decrease in ice cream firmness, although no significant difference with the reference was detected. On the contrary, the total substitution of sucrose with trehalose and erythritol resulted in a highly significant increase in firmness. For trehalose, this result may be explained by two phenomena. Firstly, freeze concentrated solutions of this sweetener have been reported to show glass transition temperatures (Tg) between $-22{ }^{\circ} \mathrm{C}$ and $-46{ }^{\circ} \mathrm{C}$ (Whelan et al., 2008a), near to the range of temperatures reached in our study during ice cream hardening and conditioning $\left(-30{ }^{\circ} \mathrm{C}\right.$ and $\left.-16{ }^{\circ} \mathrm{C}\right)$. Thus, it can be argued that during processing the formation of an amorphous phase occurs, revealing a solid-like behavior in the final matrix. Secondly, as observed by Cesàro, De Giacomo, and Sussich (2008), trehalose shows, upon cooling, a strong restriction of the solubility region, due to the reduction of sugar solubility at low temperatures but also to the formation of crystalline polymorphs much less soluble. Consequently, during cooling of a solution less concentrated than $30 \mathrm{~g} / 100 \mathrm{~mL}$, the formation and separation of ice occurs (Cesàro et al., 2008), increasing the amount of ice phase volume at the temperature of analysis $\left(-15^{\circ} \mathrm{C}\right)$, with detrimental effects on the ice cream texture (Muse \& Hartel, 2004). The increasing-firmness effect was evident also for erythritol, even with a $50 \%$ substitution level, in agreement with the extrusion behavior reported above. Due to possible changes in erythritol solubility, it can be hypothesized that at the temperature of analysis, E50 and E100 samples contained higher amount of frozen water with respect to the sucrose reference.

The results of the melting test are reported in Table 4 in terms of starting time $\left(t_{s}\right)$ and rate. Most samples, except T100, E100, and E50, showed a melting behavior comparable to REF. The total substi-
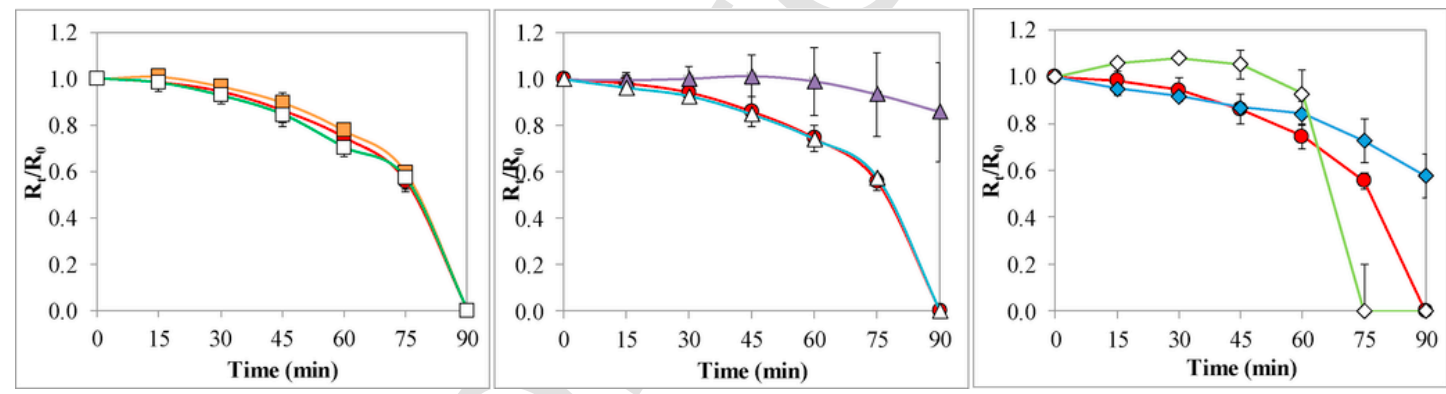

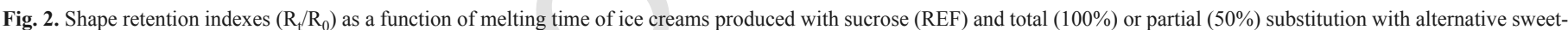

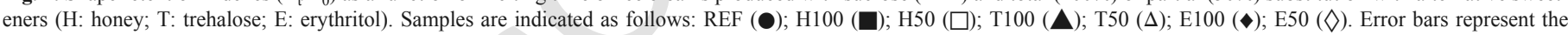
standard deviation of two technological replicates.
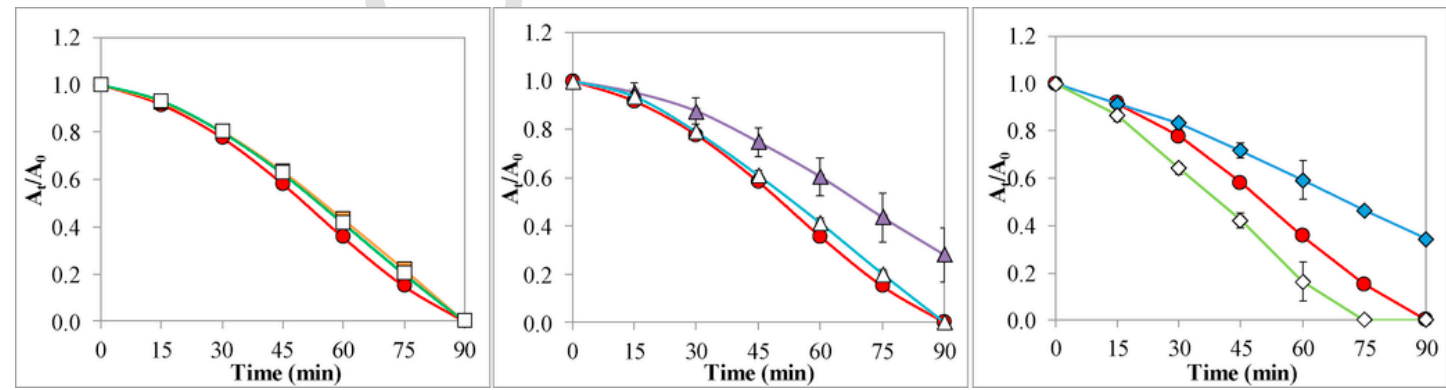

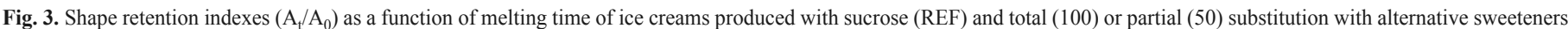

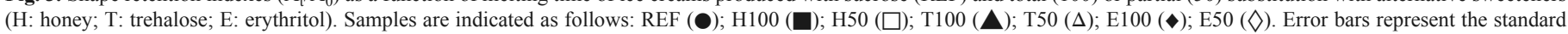
deviation of two technological replicates. 
REF

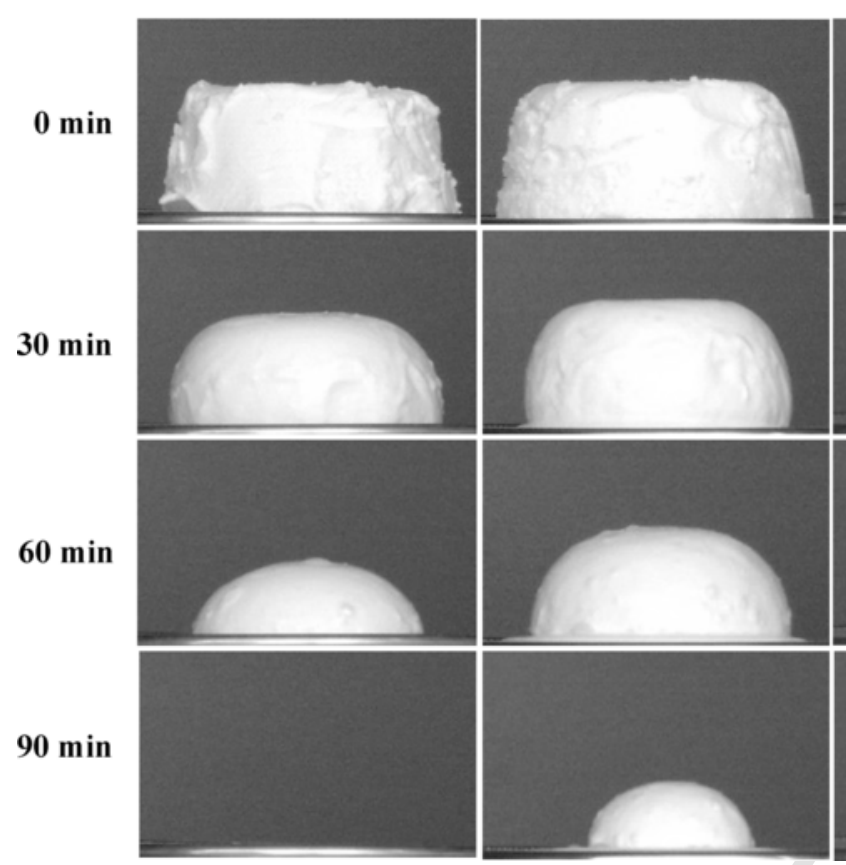

E100

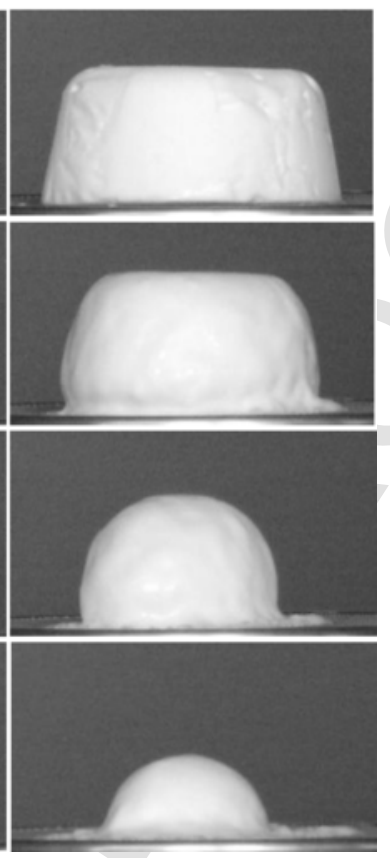

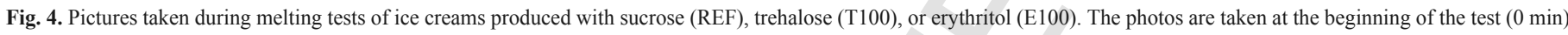
and after 30,60, and $90 \mathrm{~min}$.

tution of sucrose with trehalose (T100) and erythritol (E100) caused a significant $(\mathrm{p}<0.05)$ reduction in melting rate, probably due to the slower melting of the amorphous solid formed by the sugar during freezing and the lower solubility of these sweeteners, accounting for a higher amount of frozen water in ice creams. Unexpectedly, E50 showed a significantly $(\mathrm{p}<0.05)$ accelerated melting with respect to the other samples.

Shape retention indexes calculated during melting trials are reported in Figs. 2 and 3. The total substitution of sucrose with trehalose $(\mathrm{T} 100)$ and erythritol $(\mathrm{E} 100)$ significantly $(\mathrm{p}<0.05)$ improved the shape retention ability of ice cream (Figs. 2 and 4), resulting in $\mathrm{R}_{\mathrm{t}} / \mathrm{R}_{0}$ ratios higher than REF. Most samples, included the reference, melted down completely between 75 and 90 min, whereas T100 and E100 showed a better resistance until the end of the test, as demonstrated by the $A_{t} / A_{0}$ values at 90 min (Fig. 3) and visible in Fig. 4. These results are consistent with the above-discussed data referred to melting behavior.

\section{Conclusion}

The results of this study, filling the gap in basic knowledge about the effects of sucrose-alternative sweeteners in artisanal ice cream, represent a guideline for the successful utilization of honey, trehalose, and erythritol in peculiar ice cream formulations. The analytical data here reported can be used for a correct balance of the ice cream recipes in order to obtain a final product with the desired properties. As regards honey, only a minor effect on mix viscosity and extrusion time should be taken into account. Thanks to its nutritional properties and aromatic profile, it may be used to formulate new flavors of ice creams, able to satisfy low glycemic index dietary regimen. Erythritol and trehalose should be used in combination with other sweeteners in order to modulate ice cream firmness and melting behavior. In particular, trehalose, because of its low sweetness, can be applied in the production of non-sweet ice creams to be served with salted dishes, which are gaining an increasing market success. On the other hand, erythritol, being a non-caloric sweetener, can be used in the formulation of low calorie products. Actually, with respect to REF, ice creams E100 and E50 resulted in a calorie reduction of about $45 \%$ and $23 \%$ respectively.

\section{Acknowledgements}

This work was supported by the Italian Association of Food Product Industries (AIIPA) - "Artisanal Ice Cream Ingredients" Group.

\section{References}

Akalin, A.S., Erisir, D., 2008. Effects of inulin and oligofructose on the rheological characteristics and probiotic culture survival in low-fat probiotic ice cream. Journal of Food Science 73, 184-188.

Akalin, A.S., Karagözlü, C., Ünal, G., 2008. Rheological properties of reduced-fat and low-fat ice cream containing whey protein isolate and inulin. European Food Research and Technology 227, 889-895.

Al-Waili, N.S., 2004. Natural honey lowers plasma glucose, C-reactive protein, homocysteine, and blood lipids in healthy, diabetic, and hyperlipidemic subjects: Comparison with dextrose and sucrose. Journal of Medicinal Food 7, 100-107.

Alamprese, C., Foschino, R., Rossi, M., Pompei, C., Savani, L., 2002. Survival of Lactobacillus johnsonii Lal and influence of its addition in retail-manufactured ice cream produced with different sugar and fat concentration. International Dairy Journal 12, 201-208.

Arrigoni, E., Brouns, F., Amadò, R., 2007. Human gut microbiota does not ferment erythritol. British Journal of Nutrition 94, 643-646.

Boesten, D.M.P.H.J., den Hartog, G.J.M., de Cock, P., Bosscher, D., Bonnema, A., Bast, A., 2015. Health effects of erythritol. Nutrafoods 14, 3-9.

Busserolles, J., Gueux, E., Rock, E., Mazur, A., Rayssiguier, Y., 2002. Substituting honey for refined carbohydrates protects rats from hypertriglyceridemic and prooxidative effects of fructose. Journal of Nutrition 132, 3379-3382.

Cadena, R.S., Cruz, A.G., Faria, J.A.F., Bolini, H.M.A., 2012. Reduced fat and sugar vanilla ice creams: Sensory profiling and external preference mapping. Journal of Dairy Science $95,4842-4850$. 
Cesàro, A., De Giacomo, O., Sussich, F., 2008. Water interplay in trehalose polymorphism. Food Chemistry 106, 1318-1328.

Falguera, V., Aliguer, N., Falguera, M., 2012. An integrated approach to current trends in food consumption: Moving toward functional and organic products?. Food Control 26, 274-281.

Foster-Powell, K., Holt, S.H.A., Brand-Miller, J.C., 2002. International table of gylcemic index and glycemic load values: 2002. American Journal of Clinical Nutrition 76, 5-56.

Fuangpaiboon, N., Kijroongrojana, K., 2013. Effects of low glycemic index sweetener on coconut milk ice cream qualities. In: 2 nd International conference on nutrition and food sciences. IACSIT Press, Singapore, pp. 29-33.

Fuangpaiboon, N., Kijroongrojana, K., 2015. Qualities and sensory characteristics of coconut milk ice cream containing different low glycemic index (GI) sweetener blends. International Food Research Journal 22, 1138-1147.

Goff, H.D., Hartel, R.W., 2013. Ice cream, 7th ed. Springer, London.

Hagiwara, T., Hartel, R.W., 1996. Effect of sweetener, stabilizer, and storage temperature on ice recrystallization in ice cream. Journal of Dairy Science 79, 735-744.

Mitchell, H., 2006. Sweeteners and sugar alternatives in food technology, 1st ed. Blackwell Publishing Ltd, Oxford.

Moon, H.-J., Jeya, M., Kim, I.-W., Lee, J.-K., 2010. Biotechnological production of erythritol and its applications. Applied Microbiology and Biotechnology $86,1017-1025$

Muse, M.R., Hartel, R.W., 2004. Ice cream structural elements that affect melting rate and hardness. Journal of Dairy Science 87, 1-10.

Ozdemir, C., Dagdemir, E., Ozdemir, S., Sagdic, O., 2008. The effects of using alternative sweeteners to sucrose on ice cream quality. Journal of Food Quality $31,415-428$.
O'Brien-Nabors, L., 2001. Alternative sweeteners, 4th ed. CRC Press - Taylor \& Francis, Abington

Portmann, M.-O., Birch, G., 1996. Sweet taste and solution properties of $\alpha, \alpha$-trehalose. Journal of the Science of Food and Agriculture 69, 275-281.

Richards, B., Krakowka, S., Dexter, L.B., Schmid, H., Wolterbeek, P.M Waalkens-Berendsen, D.H., et al., 2002. Trehalose: A review of properties, history of use and human tolerance, and results of multiple safety studies. Food Chemistry and Toxicology 40, 871-898.

Rossa, P.N., Burin, V.M., Bordignon-Luiz, M.T., 2012. Effect of microbial transglutaminase on functional and rheological properties of ice cream with different fat contents. LWT-Food Science and Technology 48, 224-230.

Rossi, M., Casiraghi, E., Alamprese, C., Pompei, C., 1999. Formulation of lactose-reduced ice cream mix. Italian Journal of Food Science 11, 3-18.

Steffe, J.F., 1996. Rheological methods in food process engineering, 2nd ed. Freeman Press, East Lansing.

Sun-Waterhouse, D., Edmonds, L., Wadhwa, S.S., Wibisono, R., 2013. Producing ice cream using a substantial amount of juice from kiwifruit with green, gold or red flesh. Food Research International 50, 647-656.

Whelan, A.P., Regand, A., Vega, C., Kerry, J.P., Goff, H.D., 2008a. Effect of trehalose on the glass transition and ice crystal growth in ice cream. International Journal of Food Science and Technology 43, 510-516.

Whelan, A.P., Vega, C., Kerry, J.P., Goff, H.D., 2008b. Physicochemical and sensory optimisation of a low glycemic index ice cream formulation. International Journa of Food Science and Technology 43, 1520-1527. 